\title{
Correction to: Computational Models of Binaural Processing
}

\author{
Mathias Dietz and Go Ashida
}

\section{Correction to:}

Chapter 10 in: R. Y. Litovsky et al. (eds.), Binaural Hearing, Springer Handbook of Auditory Research 73, https://doi.org/10.1007/978-3-030-57100-9_10

In the original version of this chapter, equation (10.1) present in page 286 was published without brackets.

The correct equation

$$
\gamma(\tau)=\frac{\left\langle s(t+\tau) s^{*}(t)\right\rangle}{\left\langle|s(t)|^{2}\right\rangle}
$$

has now been updated in this revised version of this chapter.

The updated online version of this chapter can be found at https://doi.org/10.1007/978-3-030-57100-9_10 